\title{
Understanding cholesterol: high is bad but too low may also be risky - is low cholesterol associated with cancer?
}

\author{
Simko V', Ginter E ${ }^{2}$ \\ State University of New York, Downstate Medical Center at Brooklyn, USA. simko2@verizon.net
}

\begin{abstract}
Cholesterol $(\mathrm{CH})$ is a vital component of cell membranes and of their function. It is entirely justified to warn against haphazard aggressive $\mathrm{CH}$ lowering, especially now, when more effective $\mathrm{CH}$-modifying medications are entering the market. Enormous success in lowering the human toll of atherosclerosis and cardiovascular disease (CVD) by treating abnormally elevated lipids may be off set by the therapeutic risk. There are warning reports that low cholesterol is associated with malignity. There is a pressing need to evaluate all reports related to the risk of low $\mathrm{CH}$ body stores. New cholesterol management guidelines presented by American professional cardiology societies in November 2013 have reinforced the need to critically evaluate the management with statins and with other $\mathrm{CH}$ lowering medications (Tab. 1, Fig. 3, Ref. 58). Text in PDF www.elis.sk.

Key words: total cholesterol $(\mathrm{CH})$, low density lipoprotein cholesterol (LDL-C), high density lipoprotein cholesterol (HDL-C), cardiovascular disease (CVD), hydroxy-methylglutaryl coenzyme A reductase (HMGCR), randomized control trial $(\mathrm{RCT})$, cancer, statin, low cholesterol risk, lipid treatment guideline.
\end{abstract}

The overwhelming success in improving the epidemic of CVD by intensive management of lipids resulted in an oversimplified belief that $\mathrm{CH}$ has to be indiscriminately lowered. Undoubtedly, statins significantly reduced the proportion of people suffering and dying from CVD. While the CVD benefit of normalizing $\mathrm{CH}$ has been proved beyond doubt, the concerns related to consequences of abnormally low $\mathrm{CH}$ have been shrouded in controversies.

Until very recently doctors were guided by norms using the predictive value of atherogenic indices and coronary risk, proposed by the National Cholesterol Education Program in the US, the International Diabetes Federation Criteria, the European Society of Cardiology and other authoritative organizations. Indications for patient management with statins entered an innovative phase with the announcement of new cholesterol guidelines in November 2013. The American Heart Association and the American College of Cardiology drastically reshaped management that for decades had been based to targets monitored by regular blood tests. In the past people at higher CVD risk were told to get their LDL-C down as much as to 70.

From now on, individuals should be considered for a statin if their risk of heart attack or stroke in the next years is elevated by clinical criteria derived from a web- based risk calculator. These new guidelines have triggered a heated controversy among the cardiologists, patients who lost their established management rules and also the pharmaceutical industry that derives several billion dollars

${ }^{1}$ State University of New York, Downstate Medical Center at Brooklyn, USA, and ${ }^{2}$ Institute of Preventive and Clinical Medicine, Bratislava, Slovakia (emeritus)

Address for correspondence: $\mathrm{V}$. Simko MD, $\mathrm{PhD}$, State University New York, Downstate Medical Center at Brooklyn, USA.

Abbreviations: conversion index for cholesterol and LD-C: $\mathrm{mmol} / \mathrm{L}$ to $\mathrm{mg} / \mathrm{DL}$, multiply by $38.8 \mathrm{mg} / \mathrm{DL}$, to $\mathrm{mmol} / \mathrm{L}$, multiply by 0.0259 annually from statins. Critiques suggest that despite abandoning the drastic lowering of LDL-C, the actual world consumption of statins will eventually increase. Medicine is entering a new era in the management of one of the most serious health risk, the CVD.

An all-out anti-CH campaign in the past posted strict upper limits on desirable plasma level of $\mathrm{CH}$ at $5.2 \mathrm{mmol} / \mathrm{L}(201 \mathrm{mg} /$ DL). Such anti-CH enthusiasm failed to realize that $\mathrm{CH}$, like the Roman god Janus, has two images: not only the threatening one but also a friendly and beneficial. $\mathrm{CH}$ is a natural component of body metabolism that is with other lipids an essential component of cell membranes and a constituent of steroid hormones, vitamin D and bile acids. $\mathrm{CH}$ is an indispensable component of cell membranes in the brain.

A sober perspective on $\mathrm{CH}$ management should take into consideration numerous reports that revealed higher general mortality in populations with sub- normally low $\mathrm{CH}$. The Multiple Risk Factor Intervention Trial and other studies suggested increased mortality of malignant and other disorders in subjects with serum $\mathrm{CH}$ less than $3.6 \mathrm{mmol} / \mathrm{L}(140 \mathrm{mg} / \mathrm{DL})$. Men in the lowest cholesterol quintile had nearly double the cancer risk of those in the highest quintile for both incidence and mortality (1). Possible mechanisms responsible were cited as an adverse effect on the immune system and impaired cell resistance at abnormally low $\mathrm{CH}$. In the era of ever more potent anti-CH medications there is a need to call on clinicians to revise their accepted standards of management regarding optimum level of blood lipids.

\section{Controversy related to risk of cholesterol depletion versus the benefit of fighting the epidemic of atherosclerosis}

Reports warning of dire consequences when $\mathrm{CH}$ is very low have been considered controversial, mostly on behalf of employed 
methods. First, it has to be clarified what comes first, is it the low $\mathrm{CH}$ triggering a disease or is it the disease itself that causes $\mathrm{CH}$ lowering? Potential confounding factors that may cause lowering of $\mathrm{CH}$ have not been usually addressed. One-time analysis of plasma $\mathrm{CH}$ when patients are already sick is much less convincing than if low $\mathrm{CH}$ is diagnosed years before the onset of the disease that is later attributed to low $\mathrm{CH}$. Many reports omit data on food intake, effect of depression on appetite, relation to body mass index , smoking, alcohol intake, medical and addictive drugs. All these may be confounders lowering $\mathrm{CH}$ and throwing doubt on causal association between low $\mathrm{CH}$ and disease.

Data comparing epidemic of CVD and cancer contribute to $\mathrm{CH}$ controversy. Along with the dramatic success of lipid management in CVD, cancer incidence is unabated. In the 1970s the World Health Organization data indicated mortality caused by CVD to be two to three times higher than that of malignancy. This trend since then has dramatically changed (1). In many EU countries there was very significant decrease in CVD while mortality of cancer remained stable or even increased. Slovak republic in 2009 had higher cancer mortality than in 1971 (2). Poor success in combating cancer is astonishing because of important improvement in cancer diagnosis and therapy.Does this all mean theat we have now tools to combat the CVD epidemic which at the same time interfere with the management of malignancy?

\section{Cholesterol is essential for biological integrity}

Favorable results with containment of CVD epidemic lead some clinicians even to suggest optimum LDL-C to be below 1.8 $\mathrm{mmol} / \mathrm{L}$ (70 mg/DL). Such indiscriminate lowering of LDL-C might result in a failure of essential biological processes. LDL-C has an important physiological function in transporting $\mathrm{CH}$ that is necessary for the integrity of cell membranes, of which it may constitute up to $50 \%$.

Proponents of the risk related to low $\mathrm{CH}$ present serious evidence that both early cancer and advanced malignancy may be

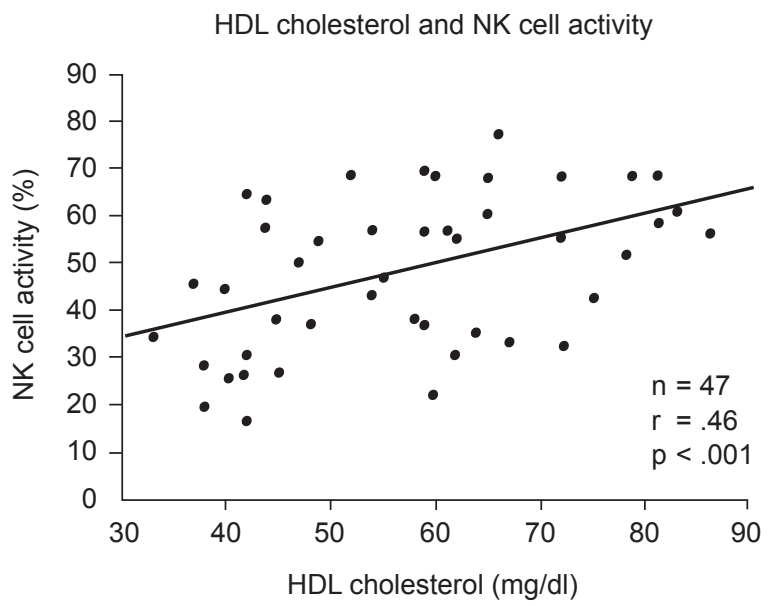

Fig. 1. Lipoproteins in the body affect the natural killer (NK) cells. Low HDL is associated with decreased NK cell activity (Ref. 8). associated with low levels of plasma $\mathrm{CH}$ and LDL-C. A common explanation has been that cancer cells might use $\mathrm{CH}$ which in turn leads to lower $\mathrm{CH}$ level. It is also possible that normal membrane function is impaired when there is a disproportionate decrease in $\mathrm{CH}$ incorporated in cancer cell membranes. The membranes of tumor cells with higher metastatic potential have a lower $\mathrm{CH} /$ phospholipid ratio. Membranes of cancer cells developing at very low plasma LDL-C have low $\mathrm{CH}$. The result is high fluidity and higher ability to resist the destructive effect of natural killer (NK) cells and cytotoxic T-cells. This phenomenon was described for cancer cells in lung and in the liver (3).

The immune system provides one of the body's main defenses against cancer. Potential for malignant transformation depends on regulatory immune processes. Initially, a limited number of cancer cells can be liquidated by anti tumor mechanisms, most importantly the NK cells and cytotoxic cells. Progression of malignity is the result of imbalance between NK cells, cytotoxic cells and the cancer cells (4) .

When normal cells turn into cancer cells, some of the antigens, T cells or T lymphocytes on their surface change. NK cells are a type of cytotoxic lymphocyte critical to the innate immune system. NK cells thar respond to tumor formation are cytotoxic: small granules in their cytoplasm contain proteins such as perforin and proteases known as granzymes. Upon release in close proximity to a cell slated for killing, perforin forms pores in the cell membrane of the target cell, creating an aqueous channel through which the granzymes and associated molecules can enter, inducing apoptosis of the cancer cell. Perforin contains an amino acid sequence which is highly homologous to a repeat unit identified in the LDL-receptor (5).

At a low $\mathrm{CH}$ the immune system is compromised since $\mathrm{CH}$ is essential for normal function of macrophages and Tlymphocytes. Male individuals with average plasma $\mathrm{CH}$ at $3.9 \mathrm{mmol} / \mathrm{L}(151 \mathrm{mg} /$ DL) when compared with a group with $\mathrm{CH} 6.8 \mathrm{mmol} / \mathrm{L}(264 \mathrm{mg} /$ DL) had less circulating T lymphocytes (6). When plasma LDL-C is low the production and activity of NK cells is impaired. Analysis of immunological data in HIV patients revealed that the percentage of NK cells was significantly lower in patients with low $\mathrm{CH}$ levels than in controls with normal $\mathrm{CH}(12.2 \pm 6$ vs. $18 \pm 11, \mathrm{p}=0.03)$. NK cell numbers were significantly correlated with $\mathrm{CH}$ levels (7). A close relationship between HDL-C and activity of NK cells was described in elderly men (8) (Fig. 1). When lipoproteins are low, activity of NK cells is also depressed and it improves when lipoprotein level goes up.

$\mathrm{CH}$ content of plasma membranes modulates the level of nitric oxide (NO). Pathological alterations in levels and distribution of cellular CH may constitute a mechanism of errant NO signaling (9). Cytokines have a crucial role in the pathogenesis of cancer (10). $\mathrm{CH}$ has also a regulatory role in cytokine metabolism. Less Interleukin-2 (IL-2) release was noted in the low, compared to the high $\mathrm{CH}$ environment. IL-2 is necessary for the growth and function of $\mathrm{T}$ cells.

Another cell line dependent on $\mathrm{CH}$ are macrophages (11). These are important tumor-infiltrating cells and play pivotal role in tumor growth and metastasis. Macrophages participate in im- 
mune responses to tumors in a polarized manner: classic M1 macrophages produce interleukin (IL) 12 to promote tumoricidal responses, whereas M2 macrophages produce IL 10 and help tumor progression.

The result of a metabolic and immune imbalance is an abnormally high number of impaired cells which thrive in the body, progressing to cancer. The initial number of cancer cells may grow out of control and eventually clinically present as cancer.

\section{Is low cholesterol associated with cancer?}

The plasma $\mathrm{CH}$ concentration correlates positively with mortality from coronary heart disease, but several studies have shown a negative relation with death from cancer. If these two relations reflect causal mechanisms that are reversible by changing the plasma $\mathrm{CH}$ concentration, the benefits of lipid reduction for heart disease might be offset by an increased mortality from cancer. What is the objective evidence?

U-shaped association between the level of blood total and LDL-cholesterol and subsequent mortality (Fig. 2) has been reported in many studies over the past decades (12-14). The righthand limb of the $U$ is the well known higher risk of death from coronary heart disease at higher levels of blood $\mathrm{CH}$. The left-hand limb of the $U$ is the higher risk of deaths from non-cardiovascular causes (e.g. cancer, depression) at lower levels of blood $\mathrm{CH}$.

Several cohort studies of healthy people have indicated that low $\mathrm{CH}$ is a risk marker for future cancer (15). There are data that cancers are associated with significantly lower $\mathrm{CH}$ level as much as 10 years before malignity surfaces clinically (4). A common explanation has been that preclinical cancers might use $\mathrm{CH}$, which would lead to lower levels of $\mathrm{CH}$ in blood. In many cohort studies (some from the 1980s) the cancer was inversely associated with $\mathrm{CH}$ measured 10-30 years earlier. The association persisted after exclusion of cancer cases appearing during the first 4 years (16-22). Unfortunately, most of these studies have looked at the relationship only at one point in time.

Relative risk of death at various cholesterol levels

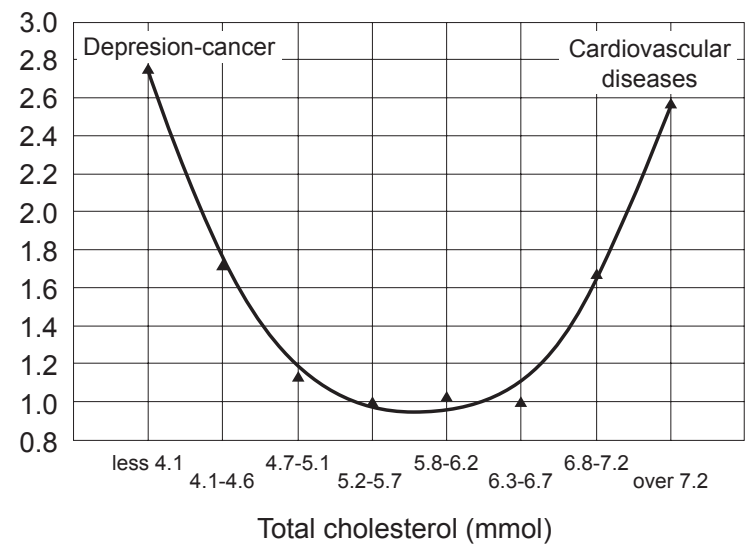

Fig. 2. Relative risk of death at various cholesterol levels (Ref. 12-14).

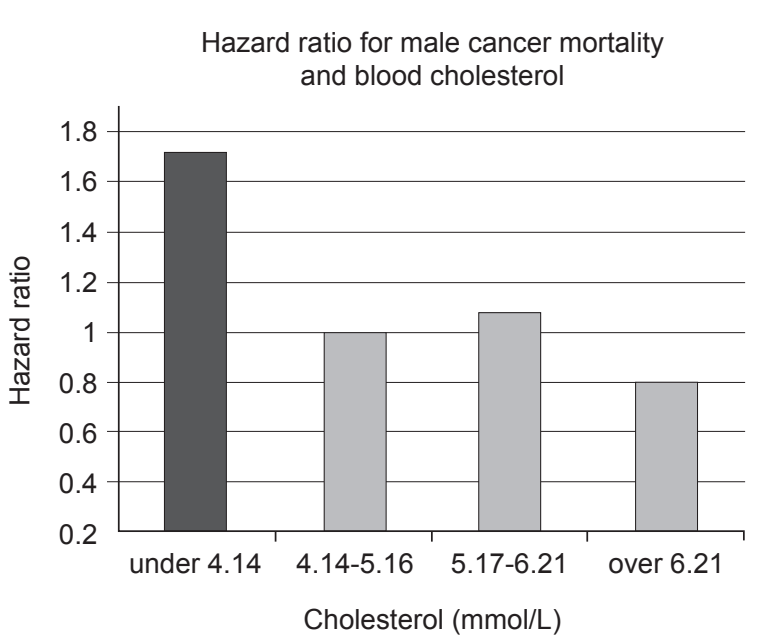

Fig. 3. Hazard ratio for male cancer mortality and blood cholesterol. (Ref. 24)

A report published more recently on over 12 thousand healthy individuals aged 40-69 years followed for 12 years, documented that males who had plasma $\mathrm{CH}$ below $4,1 \mathrm{mmol} / \mathrm{L}$ (159 mg/DL) had higher incidence of cancer (23) (Fig. 3). Benn et al (24) found that plasma LDL-C levels greater than the 66th percentile $(>3,95$ $\mathrm{mmol} / \mathrm{L}-153 \mathrm{mg} / \mathrm{DL})$ compared to those lower than the 10th percentile $(<2.23 \mathrm{mmol} / \mathrm{L}-86.5 \mathrm{mg} / \mathrm{DL})$ were associated with a 43 $\%$ decrease in the risk of cancer. Table 1 indicates potential $\mathrm{CH}$ metabolic conditions that may promote or reduce the risk of cancer.

Data from the Framingham Heart Study (FHS) offspring cohort (14) addressed some unresolved questions, mainly by eliminating the reverse-causality hypothesis that cancer is responsible for significantly lower serum concentrations of LDL-C . The forward causality hypothesis states that depressed LDL-C is a precursor of malignancy. In a retrospective, case-control study, Lavigne et al (25) examined LDL-C levels prior to cancer diagnosis. In total, 201 newly diagnosed cancer cases were propensitymatched to 402 controls who did not develop cancer. The results showed that serum LDL-C levels were inversely associated with all-cause cancer incidence. However, the relationship of LDL-C levels and time did not differ between cancer patients and healthy controls throughout an average of 18.7 years preceding diagnosis. Also, LDL-C levels in the study ,were not that low“, between 90 and $100 \mathrm{mg} / \mathrm{DL}(2.32 \mathrm{mmol} / \mathrm{L}$ and $2.58 \mathrm{mmol} / \mathrm{L})$. Another controversial finding was that LDL-C levels peaked around $135 \mathrm{mg} /$

Tab. 1. The role of cholesterol (CH) in regulation of cancerogenesis (24).

\begin{tabular}{l|l}
\hline Pro Cancerogenic & Anti Cancerogenic \\
\hline Very low $\mathrm{CH}(<4 \mathrm{mmol} / \mathrm{L})$ & Normal $\mathrm{CH}(4-6 \mathrm{mmol} / \mathrm{L})$ \\
\hline Reduced release of interleukin-2 & Normal interleukin-2 \\
\hline $\begin{array}{l}\text { Increased fluidity of cancer cell } \\
\text { membranes }\end{array}$ & Preserved cell membrane fluidity \\
\hline $\begin{array}{l}\text { Reduced production of natural } \\
\text { killer }(\mathrm{NK}) \text { and T cells }\end{array}$ & $\begin{array}{l}\text { Preserved function of NK and T } \\
\text { cells }\end{array}$ \\
\hline M2 macrophages & M1 macrophages \\
\hline Impaired NO signaling & Intact NO signaling \\
\hline
\end{tabular}


DL (3.5 mmol/L) about eight years before cancer diagnosis. The authors concluded, there is nothing to suggest that statins would be unsafe".

In a recent study by researchers at The Chinese University of Hong Kong (26), an LDL-C level of $107 \mathrm{mg} / \mathrm{DL}$ was linked to a 33 percent increased risk of cancer. Of more concern, an LDL-C level of $87 \mathrm{mg} / \mathrm{DL}$ doubled the risk of cancer. There are several more reports on the asociation of low LDL-C with cancerogenesis (27-29).

Lipid lowering therapy with its potent pharmacological effect, represents a model to test the hypothesis of $\mathrm{CH}$ association with malignancy. There seems to be controversy on the statin- cancer association, even suggesting a possibilty that statins may have a preventive potential. A pivotal role in the effect of statins has the enzyme HMGCR that was reported to inhibit the growth of malignant cells in vitro (34).

However, epidemiological studies that subjected several RCTs to meta- analysis failed to show reduced risk of cancer in statin users (30). On the contrary, twenty case control studies in over 100 thousand cancer cases, found a significant association between statin usage and cancer. But when these were stratified by cancer type, only the association with colorectal cancer remained.

A cardiology RCT analyzed the effect of long term administration of simvastatin plus Ezetimibe (blocks intestinal CH absorption) in over 800 patients with aortic stenosis. During a median follow up of 52.2 months cancer occurred more frequently in the statin-Ezetimibe group than in controls (31).

A large meta-analysis (32) included the RCTs where patients were given statins. In focus was the role of LDL-C versus HDL-C for the risk of cancer. There was a significant inverse association between HDL-C and the risk of incident cancer that was independent of LDL-C. This data is important in the present era when there is intensive attempt to therapeutically stimulate HDL-C.

\section{Evidence against a low cholesterol being associated with cancer}

Skeptic opinion is typically represented by this statement (33): „The most recent high quality evidence derived from RCTs and meta-analyses has conclusively shown there is no association between $\mathrm{CH}$ lowering with statins and the incidence of cancer. While this is accepted among the vast majority of physicians, there is a minority who continue to question the cancer safety of statins. Their concern creates challenges regarding compliance with statin therapy in patients."

There were speculations that statins, the HMGCR inhibitors, may possess cancer preventive properties (34). Poorly differentiated and well differentiated cancer cells from various organs were examined in their response to various statins (34). Inhibition of cell growth was accompanied by dramatic changes in cell morphology related to cofilin regulation and to loss of p-caveolin. These in vitro studies were not confirmed in patients. A large meta-analysis based on evaluation of 35 RCTs did not confirm the expectation of several reports that statins have chemopreventive potential against cancer (35).
Specific pharmacological effects of different statins are relevant when evaluating biological responses to statins. It should be pointed out that not all statins have the same mechanism of effect. For example, pravastatin being hydrophilic is taken up by a transporter protein exclusively in the liver. Simvastatin is hydrophobic and it enters cells by other mechanism.

The possibility regarding a potential link between statin treatment and an increased risk of cancer was again raised following cancer findings in the Cholesterol and Recurrent Events and Pravastatin in Elderly Individuals at Risk of Vascular Disease (36). The overall incidence of cancer in patients on pravastatin was not statistically significant, with the exception of elderly individuals.

Pravastatin used for five years did not result in an increase of overall cancer risk (37). In a large population of Japanese patients followed for more than 70 thousand patient years, pravastatin did not increase the cancer incidence (38).

Many more studies searched for evidence that statins may promote cancer. A pooled study of RCTs totalling 3,512 patients on fluvastatin $20-80 \mathrm{mg}$ per day, found no association between baseline LDL-C and the risk of developing cancer (39). Remarkably, fewer patients wer diagnosed with cancer in the fluvastatin group compared with placebo $(\mathrm{p}=0.03)$.

Researchers in Finland (40) subjected 42 reports to meta-analysis, with 17 RCTs, 10 cohort studies and 15 case control studies . The median folow up was 4 years. Statins had no effect on the overall incidence of cancer with an exception of weak suggestion for promoting melanoma and other skin cancer. Evidence for potentially protective or harmful influence of statins was inconclusive.

A large study using $40 \mathrm{mg}$ simvastatin daily in over 20 thousand individuals for about 5 years (41) reported that a more intensive LDL-C lowering with statin provided vascular benefits for at least 5 years without any evidence of serious hazards. In another study (42) that analyzed 15 RCTs and over 400 thousand person years in patients on statins, no association was identified regarding increased risk of cancer.

Aggressive reduction of $\mathrm{CH}$ may involve not only large doses of statins but also addition of other potent $\mathrm{CH}$ lowering drugs, for example ezetimibe that inhibits $\mathrm{CH}$ absorption from the intestine. A large post-marketing analysis on rates of cancer in patients treated with simvastatin and ezetimibe was retrieved from reports filed with the US Food and Drug Administration (FDA) (43). This large analysis, confirmed by millions of relevant drug presriptions, did not support the possibility that simvastatin with ezetimibe increase the risk of cancer.

There are also reports on specific type of malignancy in individuals whose lipids were manipulated with statins.

Because elevated lipids may facilitate progression of colorectal cancer (44), some clinicians suggested statins to prevent this type of cancer. Eighteen studies were included in a meta- analysis of data from more than 1.5 million individuals (45). There was no evidence for association between statin use and risk of colorectal cancer, either in the RCTs or in cohort studies.

Regarding prostate cancer it was suggested that high rather than low $\mathrm{CH}$ levels may promote agressive disease. A 3-year fol- 
low up of 14,241 men at risk (46) found that neither the total $\mathrm{CH}$, nor LDL-C or HDL-C were associated with the risk of progressive prostate cancer. A meta-analysis of 6 RCTs and 13 observational studies did not reveal any association between statin use and prostate cancer (47).

Relation of plasma lipids to progression of breast cancer has been the focus of other researchers. Distant metastases were significantly higher in patients with elevated total $\mathrm{CH}$, LDL-C and triglycerides (48). However, a suggestion that statins may have preventive potential in breast cancer revealed no supportive evidence for this claim in the meta-analysis of seven large RCTs and nine observational studies (49).

Regarding pancreatic cancer, the reports have initially been controversial. Therefore a comprehensive search was performed (50) on 16 studies involving over 1,69 million individuals with 7,807 pancreatic cancers. There was no association between statin use and the risk of pancreatic cancer.

Effect of statins on lipids was critically appraised in other specific types of malignancy. Statins were not documented to prevent or affect hematological malignancies (51), or melanoma (a type of skin malignancy) (52).

With large evidence expressing doubt on association of $\mathrm{CH}$ level with malignancy, several other important isues remain: What is the differential effect of various classes of statins on lipids that are essential for biological integrity and what is the consensus on a safe low level of body $\mathrm{CH}$ ?

\section{Biological response of different lipids to statins - a stimulus to reconsider limits of therapeutic lipid targeting}

Management of CVD has been mostly focused on lowering LDL-C. This lipoprotein has categorically different biological function than the HDL-C. Thus far there has been no effective theraputic tool to optimally balance all classes of lipids. Even in statins there is a difference in their effect on the cholesterol synthesizing enzyme HMGCR. When various statins (fluvastatin, simvastatin, lovastatin, pravastatin, rosuvastatin, atorvastatin) were compared regarding lowering the LDL-C in over 3 thousand diabetics (53), a marked difference was noted: most effective was rosuvastatin.

It is an oversimplifaction to equate the benefit of statin therapy with the intensity of lowering LDL-C. Biological influence of statins is much more complex. Risk of statin-associated elevated liver enzymes or rhabdomyolysis (muscle injury) was not related to achieved LDL-C levels in 23 statin treatment arms with a follow up of over 309 thousand person-years (54).

Expert panels at national and international level suggested a simplified paradigm derived from the successful outcome of CVD epidemic, attributed to lowering of total CH and LDL-C. The Adult Treatment Panel III guidelines recommend LDL-C of $<100 \mathrm{mg} / \mathrm{DL}(2.6 \mathrm{mmol} / \mathrm{L})(55)$. It is noteworthy that more than half of a large number of patients did not meet this expected lipid goal. Non compliance with statin therapy is a factor that rarely has been controlled in the overwhelmingly massive epidemiological analyses of the potential risk of statins.
Disregarding potentially confounding bias, cardiologists are sending alarm signals that despite present lipid lowering guidelines, significant CVD morbidity and mortality still occurs in a sizeable proportion of subjects receiving statins (56). Some clinicians claim that the target LDL-C of $2.6 \mathrm{mmol} / \mathrm{L}(100 \mathrm{mg} / \mathrm{DL})$ may result in undertreatment. The Heart Protection Study reported that LDL-C reduction to levels as low as $1.7 \mathrm{mmol} / \mathrm{L}$ (66 mg/DL) was associated with significant CVD benefit (57).

Therapeutic overachievers claim there is a compelling case for even more effectively targeting both the LD-C and HDL-C, to further reduce the threat of CVD to populations. They calculated that a $1 \mathrm{mmol} / \mathrm{L}$ reduction in LDL-C results in a $25 \%$ reduction in CVD risk, independent of the baseline LDL-C (57).

Considering the possbility that some of the data were obtained from patients who did not take the prescribed doses of statins and our still incomplete understanding of the biological role of various lipids, it appears imprudent to apply to lipid management a simplified rule ,the lower the better".

Pharmaceutical industry readily complies with proposals for agressive treatment. In addition to various statins as well as niacin, fibrates and ezetimibe, the body lipids will be subjected to a variety of new potent agents. These include the acyl-coenzyme A-cholesterol acyl transferase inhibitors of the microsomal transfer protein, as well as specific receptor agonists. More recently another agressive ammunition in the battle against $\mathrm{CH}$ has been reported: a monoclonal antibody that blocks PCSR9, a serin protease that enhances LDL-C by binding LDL receptors (58). Along with new discoveries in lipid management, many controversies remain unresolved. Guidelines for safe use of lipid lowering drugs should be periodically re-evaluated.

\section{Conclusion}

Body lipids participate in essential metabolic functions. While extensive epidemiological evidence in CVD supports the benefit of normalizing excessive LDL-C and enhancing HDL-C, the recommendation ,the lower the better" is non physiological. Reports in the past warned on the association of low $\mathrm{CH}$ with malignancy. This raised concern related to such additional posible undesirable side effect of statin therapy. However, many recent very extensive studies (unbiased by the pharmaceutical industry) provide no evidence that low $\mathrm{CH}$ is a risk for overall malignancy, or more specifically for colorectal, prostate, breast, hematological or skin cancer. Balancing all available information, with the development and advent of ever more potent lipid lowering medications there is a compelling need to respect the biological integrity of body lipds and devise the minimum safe lipid level.

\section{References}

1. Schatzkin A, Hoover RN, Taylor PR et al. Serum cholesterol and cancer in the NHANES I epidemiologic followup study. National Health and Nutrition Examination Survey. Lancet 1987; 2: 298-301.

2. European Health for All Database, WHO Regional Office for Europe, Copenhagen, updated January 2012. 
3. Funaki NO, Tanaka J, Kohmoto M et al. Membrane fluidity correlates with liver cancer cell proliferation and infiltration potential. Oncol Rep 2001; 8 (3): 527-532.

4. Jacobs D, Blackburn H, Higgins M et al. Report of the Conference on low blood cholesterol: mortality associations. Circulation 1992; 86: 1046-1060.

5. Tschopp J, Masson D, Stanley KK. Structural / functional similarity between proteins involved in complement-and cytotoxic T-lymphocytemediated cytolysis. Nature 1986; 322: 831-834.

6. Muldoon MF, Marsland A, Flory JD et al. Immune system differences in men with hypo- or hypercholesterolemia. Clin Immunol Immunopathol 1997; 84: 145-149.

7. Míguez MJ, Rosenberg R, Burbano X et al. Cholesterol as a mediator of alcohol-induced risks for respiratory disease hospitalizations among people living with HIV. J AIDS Clin Res 2011; Special Issue 1.

8. Yasumasu T,Kazuo T, Sadayasu T et al. Effect of plasma lipoproteins on natural killer cell activity in the elderly population . J Gerontol 2003; 58A: $561-565$.

9. Miersch S, Espey MG, Chaube R et al. Plasma membrane cholesterol content affects nitric oxide diffusion, dynamics and signaling. J Biol Chem 2008; 283 (27): 18513-18521.

10. Dranoff G. Cytokines in cancer pathogenesis and cancer therapy. Nature Reviews Cancer 2004; 4: 11-22.

11. Mosser DM, Edwards JP. Exploring the full spectrum of macrophage activation. Nature Reviews Immunology 2008; 8: 958-969.

12. International Collaborative Group: Circulating cholesterol level and risk of death from cancer in men aged 40-69 years: Experience of an international collaborative group. JAMA 1982; 248: 2853-2859.

13. Rose G, Shipley MJ. Plasma lipids and mortality: A source of error. Lancet 1980; 1: 523-526.

14. Sherwin R, Wentworth $D$, Cutler $\mathbf{J}$ et al. Serum cholesterol levels and cancer mortality in 361,662 men screened for the MRFIT. JAMA 1987; 257: 943-948.

15. Jacobs D, Blackburn H, Higgins $M$ et al. Report of the Conference on low blood cholesterol: mortality associations. Circulation 1992; 86: 1046-1060.

16. Ravnskov U, McCully KS, Rosch PJ. The statin-low cholesterolcancer conundrum. Q J Med 2012; 105: 383-388.

17. Williams RR, Sorlie PD, Feinleib M et al. Cancer incidence by levels of cholesterol. JAMA 1981; 245: 247-252.

18. Schatzkin A, Hoover RN, Taylor PR et al. Serum cholesterol and cancer in the NHANES I epidemiologic followup study. National Health and Nutrition Examination Survey. Lancet 1987; 2: 298-301.

19. Tornberg SA, Holm LE, Carstensen JM et al. Cancer incidence and cancer mortality in relation to serum cholesterol. J Natl Cancer Inst 1989; 81: 1917-1921.

20. Isles CG, Hole DJ, Gillis CR et al. Plasma cholesterol, coronary heart disease, and cancer in the Renfrew and Paisley survey. BMJ 1989; 298: 920-924.

21. Schuit AJ, Van Dijk CE, Dekker JM et al. Inverse association between serum total cholesterol and cancer mortality in Dutch civil servants. Am J Epidemiol 1993; 137 (9): 966-976.

22. Kreger BE, Anderson KM, Schatzkin A et al. Serum cholesterol level, body mass index, and the risk of colon cancer. The Framingham study. Cancer 1992; 70: 1038-1043.
23. Nago N, Ishikawa $\mathbf{S}$, Goto $\mathbf{T}$ et al. Low cholesterol is associated with mortality from stroke, heart disease, and cancer: the Jichi Medical School Cohort Study. J Epidemiol 2011; 21 (1): 67-74.

24. Benn M, Tybjærg-Hansen A, Stender S et al. Low-density lipoprotein cholesterol and the risk of cancer: a mendelian randomization study. J Natl Cancer Inst 2011; 103 (6): 508-19.

25. Lavigne PM et al. Low LDL predates cancer risk by decades. Am J Coll Cardiol 2012; 19: 59-61.

26. Yang X, So WY, Ma RC et al. Low LDL cholesterol, albuminuria, and statins for the risk of cancer in type 2 diabetes: the Hong Kong diabetes registry. Diabetes Care 2009; 32: 1826-1832.

27. DeMaria AN. Low-density lipoprotein reduction and cancer. J Amer Coll Cardiol 2007; 50: 421-422.

28. LaRosa JC. Means and ends of statins and low-density lipoprotein cholesterol lowering. J Amer Coll Cardiol 2007; 50: 419-420.

29. Yang X. Independent associations between low-density lipoprotein cholesterol and cancer among patients with type 2 diabetes mellitus. Canad Med Assoc J 2008; 179: 427-437.

30. Taylor ML, Wells BJ, Smolak MD. Statins and cancer: a meta-analysis of case- control studies. Wur J Cancer Prev 2008; 17: 259-268.

31. Rossebo AB, Pedersen TR, Boman K et al. Intensive lipid lowering with simvastatin and ezetimibe in aortic stenosis. N Engl J Med 2008; 359: 1343.

32. Jafri H, Alsheikh-Ali AA, Karas RH. Baseline and on-treatment high-density lipoprotein cholesterol and the risk of cancer in randomized controlled trials of lipid- altering therapy. J Am Coll Cardiol 2010; 55: 2846-33.

33. O'Riordan M. Statins not associated with cancer risk in large EMR database. Heart Wire 2011; July 21.

34. Menter DG, Ronnsauer VP, Harirforoosh S et al. Differential effects of pravastatin and simvastatin on the growth of tumor cells from different organ sites. PloS One 2011; 6: e 28813.

35. Bonovas $\mathbf{S}$, Filioussi $\mathbf{K}$, Tsavaris $\mathbf{N}$ et al. Statins and cancer risk: a literature- based meta- analysis and meta- regression analysis of 35 randomized controlled trials. J Clin Oncol 2006; 24: 4808-4817.

36. Bonovas S, Sitaras NM. Does pravastatin promote cancer in elderly patients? A meta- analysis. CMAJ 2007; 176: 649-654.

37. Sato S, Ajiki W, Kobayashi T et al. Pravastatin use and the five year incidence of cancer in coronary heart disease patients: from the prevention of coronary sclerosis study. J Epidemiol 2006; 16: 201-206.

38. Matsushita Y, Sugikara M, Kaburagi J et al. Pravastatin use and cancer risk: a meta- analysis of individual patient data from long-term prospective controlled trials in Japan. Pharmaco- epidemiol Drug Saf 2010; 19: $196-202$.

39. Stein EA, Corsini A, Gompelowicz CR et al. Fluvastatin treatment is not associated with an increased incidence of cancer. Int $\mathrm{J}$ Clin Pract 2006; 60: 1028-1034.

40. Knoppala J, Lamiupaa A, Pukkala E. Statins and cancer: A systematic review and meta- analysis. Eur J Cancer 2008; 44: 2122-2132.

41. Heart Protection Study Group, Bulbulia R, Bowman L, Wallendszus $\mathbf{K}$ et al. Effects on 11-year mortality and morbidity of lowering LDL cholesterol with simvastatin for about 5 years in 20,536 high-risk individuals: a randomised controlled trial. Lancet 2011; 378 : 2013-2020. 
42. Alsheikh-Ali AA, Trikalinos TA, Kent MD et al. Statins, low density liporotein cholesterol, and risk of cancer. J Am Coll Cardiol 2008; 52 : 1141.

43. Alsheikh-Ali AA, Karas RH. Ezetimibe, and the combination of ezetimibe/simvastatin, and risk of cancer: A post- marketing analysis. J Clin Lipidol 2009; 2: 138-142.

44. Notarnicola M, Altomare DF, Correale M et al. Serum lipid profile in colorectal cancer patients with and without synchronous distant metastases. Oncology 2005; 68: 371-374.

45. Bonovas S, Filioussi K, Flordeliis CS et al. Statins and the risk of colorectal cancer: a meta-analysis of 18 studies involving more than 1,5 million patients. J clin Oncol 2007; 25: 3462-3468.

46. Jacobs EJ, Stevens VL, Newton CC et al. Plasma total, LDL and HDL cholesterol and risk of aggressive prostate cancer in the Cancer Prevention Study II Nutrition Cohort. Cancer Causes Control 2012; 23: 1289-1296.

47. Bonovas S, Filioussi K, Sitaras NM. Statin use and the risk of prostate cancer: A meta- analysis of 6 randomized clinical trials and 13 observational studies. Int J Cancer 2008; 123: 899-904.

48. Liu YL, Ovian HX, Quin L et al. Association of serum lipid profile with distant metastasis in breast cancer patients. In Chinese. Zhonghua Zhong Liu Za Zhi 2012; 34: 129-131.

49. Bonovas S, Filioussi K, Tsavaris $\mathbf{N}$ et al. Use of statins and breast cancer: a meta- analysis of seven randomized controlled trials and nine observational studies. J clin Oncol 2005; 23: 8606-8612.

50. Cui X, Xie Y, Chen M et al. Statin use and risk of pancreatic cancer: a meta-analysis. Cancer Causes Control 20`12; 7: 1099-1111.
51. Bonovas S, Filioussi K, Tsantes A et al. Use of statins and risk of haematological malignancies: a meta- anlysis of six randomized clinical trials and eight observational studies. Br J Clin Pharmacol 2007; 64: 255-262.

52. Freeman SR, Drake AL, Heilig LF et al. Statins, fibrates, and melanoma risk: a systematiuc review and meta-analysis. J Natl Cancer Inst 2006; 98: 1538-1546.

53. Harley CR, Gandhi SK, Heien $H$ et al. Lipid levels and low-density lipoprotein cholesterol goal attainment in diabetic patients: rosuvastatin compared with other statins in usual care. Expert Opin Pharmacother 2008; 9: 669-676.

54. Alsheikh-Ali AA, Madduburi PV, Han $\mathbf{H}$ et al. Effect of magnitude of lipid lowering on risk of elevated liver enzymes, rhabdomyolysis, and cancer: insights from large randomized statin trials. J Am Coll Cardiol 2007; 50: 409 .

55. Alsheikh-Ali AA, Lin JL, Abourjaily $\mathbf{P}$ et al. Extent to which accepted serum lipid goals are achieved in a contemporary general medical population with coronary heart disease equivalents. Am J Cardiol 2006; 98: $1231-1233$

56. Mahdy Ali K, Wonnerk A, Huber $K$ et al. Cardiovascular disease risk reduction by raising HDL cholesterol- current therapies and future opportunities. Br J Pharmacol 2012;10.1111/j. 1476-5381.

57. Evans M, Roberts A, Davies $S$ et al. Medical lipid-regulating therapy: current evidence, ongoing trials and future developments. Drugs 2004; 64: 1181-1196.

58. Stein EA, Mellis S, Yancopoulos GD et al. Effect of a Monoclonal Antibody to PCKS9 on LDL cholesterol. N Engl J Med 2012; 366: 1108-1118.

Received October 17, 2012. Accepted October 27, 2013. 